\title{
The Family Contribution to Health Status: A Population-Level Estimate
}

\author{
Robert L. Ferrer, MD, MPH \\ Ray Palmer, $P b D$ \\ Sandra Burge, $P b D$
}

Department of Family and Community Medicine, University of Texas Health Science Center at San Antonio, San Antonio, Tex
Conflicts of interest: none reported

\section{CORRESPONDING AUTHOR}

Robert L. Ferrer, MD, MPH

Department of Family and Community

Medicine

University of Texas Health Science Center

at San Antonio

7703 Floyd Curl Drive

San Antonio, TX 78229-3900

ferrerr@uthscsa.edu

\begin{abstract}
PURPOSE Clinical studies have shown strong family influences on individual health, but the aggregate importance of family effects for population health is unknown. Our objective was to estimate, at a population level, the variance in individual health status attributable to the family.

METHODS Secondary data were used from the Community Tracking Study, a stratified random sample of the US population. Hierarchical linear modeling was used to estimate the individual and family components of health status. The setting was 60 US communities, which account for approximately one half of the population. Participants were US residents aged 18 years and older who shared a household with family members in the study ( $N=35,055)$. Main outcome measures were the Short Form-12 (SF-12) self-reported physical and mental subscales.
\end{abstract}

RESULTS Depending on the family configuration, $4.5 \%$ to $26.1 \%$ of the variance in individual health status was derived from the family. The proportion was highest for older married persons. The family effect on health status was generally similar for physical and mental health. Including age, family income, and health insurance status in the regression equations moderately reduced the family variance component.

CONCLUSIONS At a population level, the family contribution to individual health status is measurable and substantial. The shared characteristics of income and health insurance account for only a modest portion of the effect. Health policy and interventions should place more emphasis on the family's role in health.

Ann Fam Med 2005;3:102-108. DOI: 10.1370/afm.266

\section{INTRODUCTION}

$\mathrm{S}$ ince its publication in 1977, George Engel's biopsychosocial model has provided the conceptual underpinning for family medicine and other primary care disciplines. ${ }^{1}$ Writing in response to the biomedical reductionism that had taken hold in mainstream medicine, Engel underlined the importance of understanding health and illness in a multilevel context. The contribution of the biopsychosocial model has been to emphasize the embeddedness of each person in a continuum of hierarchies from the molecular to the societal and the role that each level of organization plays in determining health outcomes. Despite its theoretical power, however, the complexity of the biopsychosocial model has made it difficult to test empirically in a multilevel framework.

Nevertheless, a large body of research has addressed both family and community influences on health. Family-level influences on health derive from 3 main sources: genetics, a shared physical environment, and a shared social environment. ${ }^{2}$ The last 2 factors become more important when family members inhabit the same household. The shared social environment includes functional relationships, such as caregiving; shared socioeconomic circumstances, such as income and wealth, that are linked to barriers and opportunities for healthy living; and shared relationships, 
both positive and negative. Family effects have been identified for a wide variety of specific health outcomes in both adults and children. ${ }^{3-10}$ In addition, a growing body of research during the last 2 decades has demonstrated the effects on individual health outcomes of community-level characteristics above and beyond the effect of individual-level variables. ${ }^{11}$ Mortality, cardiovascular disease, violence, and other outcomes are influenced by the economic, racial/ethnic, and social characteristics of neighborhoods and larger social aggregations. ${ }^{2,13}$

In this study, we ask a different question: instead of considering specific disease outcomes for individuals, we ask what the contextual effects of family and community on individual health status are at a population level. That is, across the US population, what proportion of general health status can be attributed to individual-, family-, and community-level determinants? Our intent is not to disentangle the contribution of specific family and community environmental determinants, but to estimate the public health importance of the pathways taken as a whole. To our knowledge, this study is the first to address this question. From a population or public health perspective, addressing this question is important to understand the determinants of illness and well-being and also to inform policy on health interventions.

\section{METHODS}

\section{Data Source}

This study is a secondary analysis of data from the Community Tracking Study (CTS), which was administered to a stratified random sample of the US population between July 1996 and July 1997. Respondents completed an automated telephone survey; provision was made to respondents without telephones by allowing them to access the survey by cellular telephone. Survey questions covered demographics, health insurance, satisfaction with health care, use of health services, and health status. The response rate was $65 \%$. Because only adults completed the health status questions, we limited our analysis to responses from persons aged 18 years or older who shared a household with a spouse or at least 1 child $(\mathrm{N}=35,055)$.

\section{Measures}

The health status questions administered included the Short Form-12 questionnaire (SF-12), a validated health status instrument with 2 subscales that cover mental and physical health status. ${ }^{14}$ The overall SF-12 score is scaled to have a mean of 50 with a standard deviation of 10 . The physical component summary and mental component summary scores were used for this study.
The physical component summary scale is constructed from SF-12 items covering physical limitations, role functioning, pain, and general health status. The mental component summary scale is constructed from items on emotional problems, role functioning, and mood.

\section{Analysis}

In the CTS data set, 3 nested levels can be used to define families. ${ }^{15}$ The most restricted definition, the family insurance unit, includes an adult head of household, a spouse (if present), dependent children up to the age of 18 years who are living in the household, or children aged 18 to 22 years who are in school even if they are living elsewhere. A census family, so named because it most closely corresponds to the definition used by the Census Bureau, includes all persons related to the head of household by blood or marriage. Finally, a household includes all persons residing together.

We chose to use the census family definition for 3 reasons. First, we wanted to include relatives who shared the residence with the family insurance unit. Second, because there was no relationship code other than "spouse" for cohabiting adults, the household definition had the potential for misclassifying respondents as family members when they were actually housemates or boarders. Third, a family-level weight was available for census families, but not households, thus allowing more accurate population-level point estimates. We tested the sensitivity of our analysis to the choice of household vs census family definition by rerunning the analysis; the results were nearly identical.

We defined family configurations according to a CTS-constructed variable that categorized persons as belonging to 1 of the following family classifications: "single," "single with kids," "married, no kids," "married with kids," or "non-nuclear family." The CTS further subdivided households into single-family households ( $84 \%$ of households) and multiple-family households (16\%), depending on whether there was more than 1 family insurance unit in the household. Most (55\%) persons in the additional family insurance units within households were either parents or grandchildren of the adult head of household. We chose to analyze multiplefamily households separately because we hypothesized that these varied living arrangements might materially alter the family environment.

Communities were defined as the 60 CTS sitesgenerally cities or aggregations of rural counties. Although we recognized this definition of community to be coarse, smaller geographic units were not available in the public-use data set. We analyzed the individual-, family-, and community-level influences on self-rated health in a hierarchical linear model by using MLWin (Centre for Multilevel Modelling, London) 
software. The hierarchical linear model accounts for the nested data structure of individuals within families and families within communities.

All analyses applied personlevel and family-level weights appropriate for making estimates representative of the noninstitutionalized US population. Because currently available hierarchical linear model software does not account for the design effect from clustered sampling, in which the actual variance is greater than what it would be under the assumption of simple random sampling, ${ }^{16}$ we recomputed all standard errors before calculating statistical significance. The average design effect across the CTS variables is 3.7 (ie, the actual variance is 3.7 times what it would be if the survey were a simple random sample), ${ }^{15}$ so we rechecked statistical significance after multiplying the estimated standard errors by 1.92 (the square root of 3.7 ).

\section{The Multilevel Model}

We used the hierarchical linear model to examine health status in individuals, families, and communities. The individual-level model (level-1) is a fixed-effects linear model that predicts health status for each individual as a function of the family-specific mean plus an error term. The family-level model (level-2) expresses the family-specific mean as a function of the mean of all families plus an error term. By substituting the level-2 equation into the level-1 equation, a combined multilevel model is generated, and a similar procedure generates the community-level model (level-3). ${ }^{17} \mathrm{Within}$ the combined model, the variance at each level is calculated and can be used to compute an intraclass correlation coefficient, which, for this study, is equal to the family-level variance divided by the sum of the individual- and family-level variances. It is a measure of the proportion of the variability in health status between, rather than within, families.

Our initial analysis used the combined level-3
Table 1. Family Composition by Type of Household ( $N=35,055)$

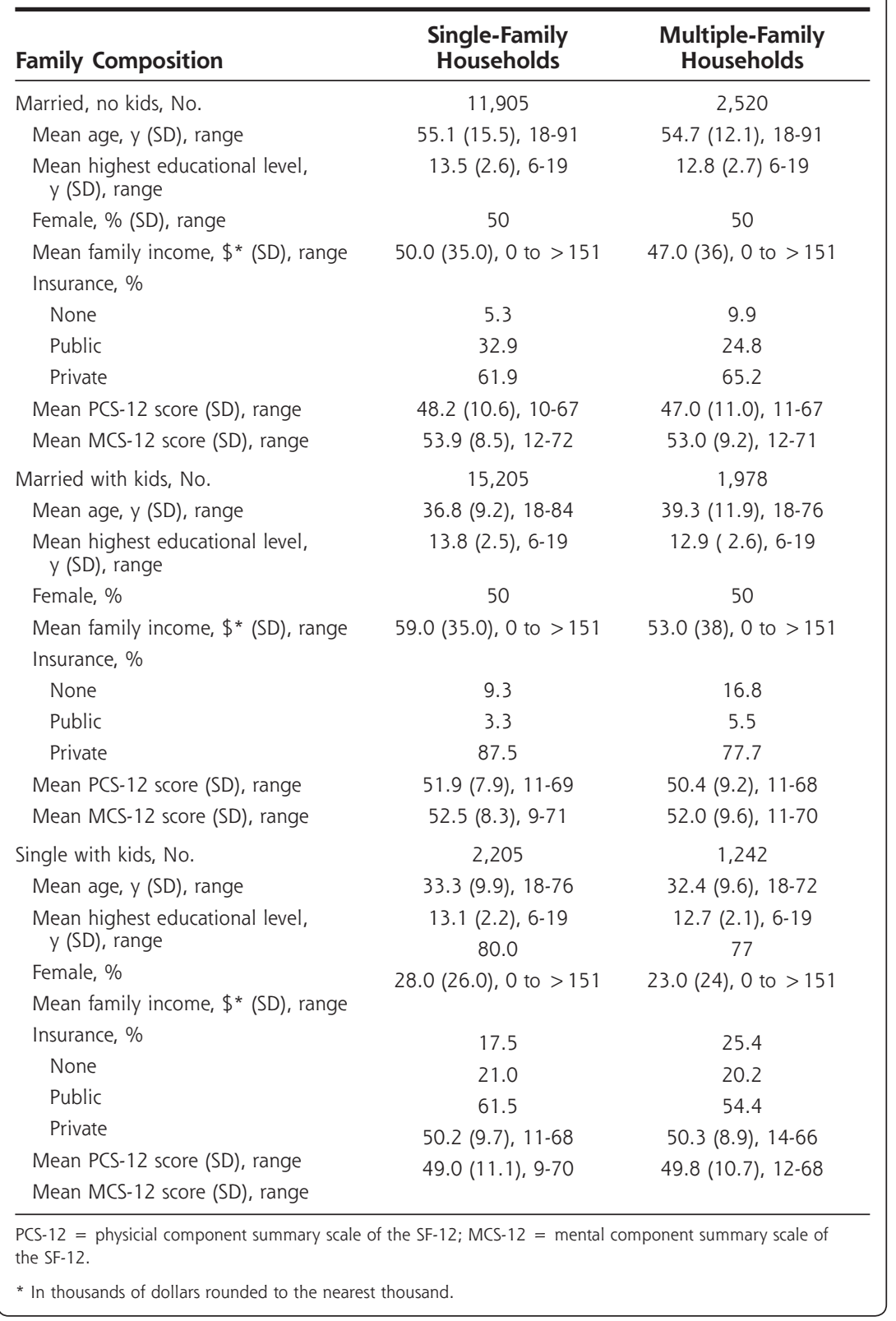

model to partition the variance of the SF-12 scores into 3 components: individual (level-1), family (level-2), and community (level-3). Because the community level accounted for less than $1 \%$ of the total variance in health status scores in initial analyses, however, subsequent analyses were limited to the individual (level-1) and family (level-2) components. The second analysis was a series of multilevel regression equations that sequentially added age, family income, and then health insurance status as predictors of SF-12 scores. For this set of equations, we were interested in assessing the proportion of family-level variance accounted for as each covariate was added to the model. 


\begin{tabular}{|c|c|c|c|c|c|c|}
\hline \multirow[b]{2}{*}{ Family Composition } & \multicolumn{3}{|c|}{ Individual } & \multicolumn{3}{|c|}{ Family } \\
\hline & Level-1 Var & SE & $\%$ & Level- 2 Var & SE & $\%$ \\
\hline \multicolumn{7}{|l|}{ Single-family households } \\
\hline Married, no kids & 88.48 & 4.43 & 77.7 & 25.43 & 3.72 & 22.3 \\
\hline Married with kids & 55.14 & 3.11 & 86.8 & 8.44 & 2.00 & 13.2 \\
\hline Single with kids & 77.59 & 11.13 & 76.9 & 23.31 & 9.38 & 23.1 \\
\hline \multicolumn{7}{|l|}{ Multiple-family households } \\
\hline Married, no kids & 103.05 & 11.50 & 83.9 & 19.85 & 8.65 & 16.1 \\
\hline Married with kids & 70.66 & 9.20 & 83.9 & 13.53 & 6.33 & 16.1 \\
\hline Single with kids & 75.93 & 14.64 & 95.5 & 3.64 & 9.16 & $4.5^{*}$ \\
\hline
\end{tabular}

Table 3. Multilevel Variance Components for SF-12 Mental Health Summary Score

\begin{tabular}{lrrrrrr}
\hline & \multicolumn{3}{c}{ Individual } & \multicolumn{3}{c}{ Family } \\
\cline { 2 - 7 } Family Composition & Level-1 Var & SE & $\%$ & Level-2 Var & SE & $\%$ \\
\hline Single-family households & & & & & & \\
$\quad$ Married, no kids & 58.20 & 3.50 & 80.8 & 13.84 & 2.67 & 19.2 \\
$\quad$ Married with kids & 58.80 & 3.13 & 82.7 & 12.37 & 2.24 & 17.3 \\
$\quad$ Single with kids & 115.23 & 20.81 & 84.0 & 22.13 & 16.99 & $16.0^{*}$ \\
Multiple-family households & & & & & & \\
$\quad$ Married, no kids & 61.94 & 7.18 & 73.9 & 21.83 & 7.41 & 26.1 \\
$\quad$ Married with kids & 80.97 & 10.91 & 85.9 & 13.26 & 6.09 & 14.1 \\
Single with kids & 95.22 & 24.92 & 91.6 & 19.20 & 22.74 & $16.7^{*}$ \\
\hline
\end{tabular}

Var = variance; SE $=$ Standard Error; SF-12 = Short Form-12.

* Not significant.

\section{RESULTS}

Descriptive statistics of the sample and study variables, including the number and proportion of various family structures for CTS participants, are shown in Table 1. The multilevel variance components for the SF-12 physical and mental health summary scores appear in Tables 2 and 3. The family (level-2) variance component ranged from $4.5 \%$ to $26.1 \%$ for the physical health score and from $14.1 \%$ to $26.1 \%$ for the mental health score. All the level-2 variance components for physical health were statistically significant except for single persons with children in multiple-family households. All the level-2 variance components for mental health were statistically significant except for single persons with children in single- or multiple-family households. The level-2 variance component was generally similar for mental and physical health status. Level-2 variances between single- and multiple-family households were comparable. For this reason, only single-family households were used in the regression models

In the multilevel regression models, age and income were significant predictors of physical health status in all family configurations (Table 4). The effects were in the expected direction; older age, lower income, and lack of insurance were associated with worse physical health status. Age accounted for approximately $30 \%$ of the level-2 variance for physical health status in the "married, no kids" group, reducing the family-level variance component from $22.3 \%$ to $16.2 \%$ of the total variance. This magnitude of effect was not observed in the "married with kids" or the "single with kids" groups. Adding income to the regression equations further reduced the level-2 variance component by $23 \%$ to $60 \%$ in all family configurations. After adjustment for age and income, insurance status only slightly improved the model.

The multilevel regression models for mental health status displayed a different pattern (Table 5). Income remained a significant predictor in all family configurations, but age accounted for a very small amount of level-2 variation and was significant only in the "married, no kids" families. Insurance status also accounted for little of the level-2 variance. Adjustment for covariates had smaller effects on the level-2 variance components for mental health than for physical health.

\section{DISCUSSION}

At the population level, the contribution of the family unit to self-rated health status is substantial: the familylevel variance accounts for $4.5 \%$ to $26.1 \%$ of the total variance in individual physical and mental health status. The family-level effect is most pronounced in married persons without children living in the household, probably because this group has the oldest average age of any of the family configurations ( 56.0 years, vs 36.6 years for "married with kids" and 33.2 years for "single with kids") and thus contains persons who have had the longest exposure to the shared family environment. This hypothesis is supported by the observation that including age as a covariate in equations predicting health status 


\begin{tabular}{|c|c|c|c|c|c|c|}
\hline $\begin{array}{l}\text { Family } \\
\text { Composition }\end{array}$ & Intercept & $\begin{array}{l}\text { Age } \\
\text { Years }\end{array}$ & Income* & $\begin{array}{c}\text { Insurance } \\
\text { Status }^{\dagger}\end{array}$ & $\begin{array}{c}\text { Level-2 } \\
\text { Variance, \% } \\
\end{array}$ & $-2 * \log L^{\ddagger}$ \\
\hline \multicolumn{7}{|l|}{ Married, no kids } \\
\hline Model 1 & $48.05(0.23)$ & - & - & - & 22.3 & 89,725 \\
\hline Model 2 & $58.11(0.63)$ & $-0.18(0.02)$ & - & - & 16.2 & 88,942 \\
\hline Model 3 & $50.93(1.10)$ & $-0.15(0.02)$ & $1.65(0.15)$ & - & 12.5 & 88,510 \\
\hline Model 4 & $48.75(1.30)$ & $-0.13(0.02)$ & $1.47(0.20)$ & $1.25(0.42)$ & 12.6 & 88,452 \\
\hline \multicolumn{7}{|c|}{ Married with kids } \\
\hline Model 1 & $51.82(0.16)$ & - & - & - & 13.2 & 105,957 \\
\hline Model 2 & $54.62(0.62)$ & $-0.08(0.02)$ & - & - & 13.5 & 105,851 \\
\hline Model 3 & $51.06(0.74)$ & $-0.10(0.02)$ & $1.28(0.16)$ & - & 10.1 & 105,398 \\
\hline Model 4 & $50.65(0.80)$ & $-0.11(0.02)$ & $1.19(0.16)$ & $0.44(0.14)$ & 9.9 & 105,376 \\
\hline \multicolumn{7}{|l|}{ Single with kids } \\
\hline Model 1 & $49.62(0.54)$ & - & - & - & 23.31 & 16,289 \\
\hline Model 2 & $53.91(1.72)$ & $-0.13(0.06$ & - & - & 22.05 & 16,257 \\
\hline Model 3 & $50.80(1.73)$ & $-0.17(0.06)$ & $2.14(0.42)$ & - & $8.8^{\S}$ & 16,141 \\
\hline Model 4 & $50.51(1.88)$ & $-0.017(0.06)$ & $2.03(0.46)$ & $0.39(1.62)^{\S}$ & $8.6^{\S}$ & 16,137 \\
\hline \multicolumn{7}{|c|}{ SF-12 = Short Form-12. } \\
\hline \multicolumn{7}{|c|}{$\begin{array}{l}\text { * Income quintile, } 1=\text { lowest, } 5=\text { highest. } \\
\dagger \text { Insured. } \\
\neq-2 * \text { LogL is a goodness-of-fit statistic. Smaller numbers indicate a better model fit. } \\
\S \text { Not significant. }\end{array}$} \\
\hline
\end{tabular}

\begin{tabular}{|c|c|c|c|c|c|c|}
\hline $\begin{array}{l}\text { Family } \\
\text { Composition }\end{array}$ & Intercept & $\begin{array}{l}\text { Age } \\
\text { Years }\end{array}$ & Income* & $\begin{array}{l}\text { Insurance } \\
\text { Status }^{\dagger}\end{array}$ & $\begin{array}{c}\text { Level-2 } \\
\text { Variance, \% }\end{array}$ & $-2 * \log L^{\ddagger}$ \\
\hline \multicolumn{7}{|l|}{ Married, no kids } \\
\hline Model 1 & $53.99(0.18)$ & - & - & - & 19.8 & 84,438 \\
\hline Model 2 & $51.57(0.65)$ & $0.04(0.01)$ & - & - & 18.8 & 84,355 \\
\hline Model 3 & $48.35(0.92)$ & $0.06(0.02)$ & $0.75(0.15)$ & - & 17.8 & 84,227 \\
\hline Model 4 & $47.56(1.24)$ & $0.06(0.02)$ & $0.68(0.15)$ & $0.44(0.36)^{\S}$ & 17.7 & 84,219 \\
\hline \multicolumn{7}{|c|}{ Married with kids } \\
\hline Model 1 & $52.47(0.17)$ & - & - & - & 17.3 & 107,338 \\
\hline Model 2 & $51.70(0.66)$ & $0.02(0.02)^{\S}$ & - & - & 17.4 & 107,321 \\
\hline Model 3 & $49.78(0.81)$ & $0.01(0.02)^{\S}$ & $0.68(0.16)$ & - & 16.5 & 107,216 \\
\hline Model 4 & $49.25(0.94)$ & $0.01(0.02)^{\S}$ & $0.56(0.18)$ & $0.57(0.34)^{\S}$ & 15.4 & 107,189 \\
\hline \multicolumn{7}{|l|}{ Single with kids } \\
\hline Model 1 & $48.42(0.70)$ & - & - & - & $16.0^{\S}$ & 16,889 \\
\hline Model 2 & $49.06(2.50)$ & $-0.02(0.06)^{\S}$ & - & - & 16.1 & 16,889 \\
\hline Model 3 & $47.15(2.70)$ & $-0.04(0.06)^{\S}$ & $1.23(0.54)$ & - & 14.5 & 16,854 \\
\hline Model 4 & $46.42(2.48)$ & $-0.04(0.06)^{\S}$ & $0.99(0.64)$ & $0.85(1.12)$ & 13.5 & 16,844 \\
\hline \multicolumn{7}{|c|}{ SF-12 = Short Form-12. } \\
\hline \multicolumn{7}{|c|}{$\begin{array}{l}\text { * Income quintile, } 1=\text { lowest, } 5=\text { highest. } \\
+ \text { Insured. } \\
\text { †-2*LogL is a goodness-of-fit statistic. Smaller numbers indicate a better model fit. } \\
\S \text { Not significant. }\end{array}$} \\
\hline
\end{tabular}

substantially reduces the level-2 variance component for physical health in the "married with kids" group. As expected, income is an important feature of the family environment, exerting a measurable independent influence on the level-2 variance component, whereas insur- ance status has smaller effects. With our limited number of predictors, $40 \%$ to $80 \%$ of the family-level variance component remains unexplained in our models.

Numerous studies have found family-level effects on health behaviors and illness. For example, spouses have 
higher odds than age-matched controls for concordance on coronary risk factors; diseases such as asthma, depression, hypertension, dyslipidemia, and peptic ulcer disease ; and suicide..$^{7-10}$ These observations strongly suggest that rational clinical services should be designed to take into account family-level influences. For example, although the traditional gathering of family history has emphasized seeking genetic linkages, the strength of spousal concordance for many chronic diseases emphasizes that shared environmental risks are also important; thus, a spouse's illness profile is useful for predicting risk.

The influence of genetic factors on concordant health status in this study was probably small for methodologic reasons. Spouses constituted the great majority $(87 \%)$ of adults whose health status was evaluated in the multilevel model. Most of the family-level effect, therefore, derived from shared features of the family environment rather than from shared genetics. Of note is that the only nonsignificant level-2 variances were observed in the subgroup with potentially the closest genetic relationship — "single with kids" — whose intrafamily correlations were derived mainly from single parents and their young-adult children. Many of these children could be assumed to be living outside the household. The effect of a shared physical environment and more frequent interactions is thereby lost.

Family environmental factors take many forms, including mutually practiced health beliefs and behaviors, shared physical environments, common stresses arising from family illnesses or deaths, instrumental support for obtaining health care, and interpersonal relations that can be either beneficial or deleterious to health. ${ }^{18-20}$ The cumulative population-level effect of the family environment on health will be determined by the epidemiology of these family-level factors. One of the most powerful determinants of family risk (which is evident in our analysis) is socioeconomic position, ${ }^{21-23}$ which is generally shared by cohabiting family members and which strongly stratifies many nongenetic risk factors. The effect of socioeconomic position is to structure a set of life circumstances-quality of housing, neighborhood conditions, transportation, and access to medical care-each of which carries health implications. ${ }^{24,25}$ Family systems research has documented that different patterns of family dynamics predict different health outcomes. ${ }^{26}$ We do not know, however, how the epidemiology of family dynamics cumulates into population patterns of morbidity and mortality.

With the exceptions of income and health insurance coverage, this study does not elaborate on the contribution of the various family environmental pathways; rather, it seeks to estimate the public health importance of the pathways taken as a whole. By understanding the relative contributions to health of various levels of the biopsychosocial continuum, proper weight can be given to these levels in designing policy and interventions. Although it does not automatically follow that the solution to a family-level problem has to be applied at the family level (for instance, spouses concordant for depression or obesity can individually be offered behavioral counseling or medication), there may be fruitful ways to manage common risk for multiple morbidities in multiple family members through family interventions; the emphasis on individual clinical care has impeded exploration of such interventions.

This study is subject to several important limitations. First is our definition of family. Defining family can be an elusive task, but a generally accepted definition is a group of intimates who have a history and a future as a group. ${ }^{27}$ Using data from a large epidemiologic study, we instead had to rely on fixed-category self-reports of family configurations. Second, we lacked information on how long respondents had been in their current family configuration. To the extent that there is a true family effect, attempting to measure that effect in persons who have been in a family constellation for brief periods will underestimate its importance. Third, because the CTS limited its geographic identifiers in the public-use data set to the level of cities and counties, our definition of community was coarse, and we almost certainly underestimated the effect of communities (neighborhoods) on health status. A robust array of studies has documented pervasive community-level effects on morbidity and mortality. ${ }^{11,13,28}$ Fourth, we examined only 1 category of health outcomes (self-reported health status) and can make no inferences about the population-level contribution of family to other important outcomes, such as mortality, functional status, and specific morbidities. Fifth, assortative mating - the tendency for people who share traits to form couplesmay account for part of the family effect, although the lesser family variance component for young couples suggests that assortative mating has limited explanatory power for health status. Finally, the amount of variation attributed to a particular hierarchical level in a multilevel model does not necessarily predict the strength of the explanatory variables that operate at that level. ${ }^{29}$ For instance, if there were little between-community variability in health status, then the model would assign little variance to that level, even though community-level variables might exert strong effects on health status.

In conclusion, using data from a nationally representative US sample, we found a substantial populationlevel contribution of the family to health status. With the availability of multilevel modeling as an analytical tool, further refinements in the understanding of the family's role in population health status should follow and contribute both to the basic science of family practice and to the development of policy and interventions. 
To read or post commentaries in response to this article, see it online at http://www.annfammed.org/cgi/content/full/3/2/102.

Key words: Health status; family; health surveys

Submitted April 26, 2004; submitted, revised, September 22, 2004; accepted October 20, 2004.

Funding support: Dr Ferrer was supported by a Robert Wood Johnson Foundation Generalist Physician Faculty Scholar Award during the time this work was performed.

A version of this paper was presented the North American Primary Care Research Group 31st Annual Meeting, Calgary, Alberta, Canada, October 25-29, 2003.

\section{References}

1. Engel GL. The need for a new medical model. Science. 1977;196: 129-136.

2. Medalie JH, Cole-Kelly K. The clinical importance of defining family. Am Fam Physician. 2002;65:1277-1279.

3. Doherty WJ, Campbell TJ. Families and Health. Newbury Park, Calif: Sage Publications; 1988.

4. Hippisley-Cox J, Pringle M. Are spouses of patients with hypertension at increased risk of hypertension? A population based case-control study. Br J Gen Pract. 1998;46:1580-1584

5. Friedman GD, Quesenberry Jr CP. Spousal concordance for cancer incidence: a cohort study. Cancer. 1999;86:2413-2419.

6. Galbaud Du Fort G, Kovess V, Boivin JF. Spouse similarity for psychological distress and well-being: a population study. Psychol Med. 1994;24:431-447.

7. Sackett DL, Anderson GD, Milner R, Feinleib M, Kannel WB. Concordance for coronary risk factors among spouses. Circulation. 1975;52:589-595.

8. Kolonel LN, Lee J. Husband-wife correspondence in smoking, drinking, and dietary habits. Am J Clin Nutr. 1981;1:99-104.

9. Hippisley-Cox J, Coupland C, Pringle M, Crown N, Hammersley V. Married couples' risk of same disease: cross-sectional study. BMJ. 2002;325:636-640

10. Agerbo E. Risk of suicide and spouse's psychiatric illness or suicide: nested case-control study. BMJ. 2003;327:1025-1026.

11. Robert SA. Socioeconomic position and health: the independent contribution of community socioeconomic context. Ann Rev Sociol. 1999;25:489-516.
12. Sampson RJ, Raudenbush SW, Earls F. Neighborhoods and violent crime: a multilevel study of collective efficacy. Science. 1997;277:918-924

13. Waitzman NJ, Smith KR. Phantom of the area: poverty area residence and mortality in the United States. Am J Public Health. 1998;88:973-976.

14. Ware Jr. JE, Kosinski M, Keller S. A 12-item Short-Form Health Survey. Med Care. 1996;34:220-233.

15. Center for Studying Health System Change. User Guide for Public-Use Version of the Main Dataset. Ann Arbor, Michigan: Inter-University Consortium for Political and Social Research; 2000.

16. Lee ES, Forthofer RN, Lorimer RJ. Analyzing Complex Survey Data. Newbury Park, Calif: Sage Publications; 1989.

17. Bryk AS, Raudenbush SW. Hierarchical Linear Models. Newbury Park, Calif: Sage Publications; 1992.

18. Committee on Health and Behavior. Health and Behavior: The Interplay of Biological, Behavioral, and Societal Influences. Washington, DC: National Academy Press; 2001.

19. House JS, Landis KR. Social relationships and health. Science. 1988; 241:540-545.

20. Seeman TE, McEwen BS. Impact of social environment characteristics on neuroendocrine regulation. Psychosom Med. 1996;58:459-471.

21. Williams DR, Collins C. US socioeconomic and racial differences in health: patterns and explanations. Ann Rev Sociol. 1995;21:349-386.

22. Davey Smith G, Neaton JD, Wentworth D, Stamler R, Stamler J. Socioeconomic differentials in mortality risk among men screened for the Multiple Risk Factor Intervention Trial: I. White Men. Am J Public Health. 1996;86:486-496.

23. Adler N, Boyce T, Chesney MA, et al. Socioeconomic status and health: the challenge of the gradient. Am Psychologist. 1994;49:15-24.

24. Lynch JW, Kaplan GA. In: Berkman LF, Kawachi I, eds. Social Epidemiology. Oxford: Oxford University Press; 2000.

25. Pearlin LI. The sociological study of stress. J Health Soc Behav. 1989;30:241-256.

26. Fisher L, Ransom DC. An empirically derived typology of families: 1. Relationships with adult health. Fam Process. 1995;34:161-182.

27. Ransom DC, Vandevoort HC. The development of family medicine: problematic trends. JAMA. 1973;225:1098.

28. Diez Roux AV, Merkin SS, Arnett D, et al. Neighborhood of residence and incidence of coronary heart disease. $N$ Engl J Med. 2001;345:99-106.

29. Bingenheimer JB, Raudenbush SW. Statistical and substantive inferences in public health: issues in the application of multilevel models Annu Rev Public Health. 2004;25:53-77. 